\title{
Partial Splenic Embolization for Lenvatinib Therapy-associated Thrombocytopenia Among Patients With Hepatocellular Carcinoma
}

\author{
NOBUTAKA SATO ${ }^{1}$, TORU BEPPU ${ }^{1}$, KOICHI KINOSHITA ${ }^{1}$, HIDEAKI YUKI ${ }^{2}$, KOICHI SUYAMA ${ }^{3}$, \\ HIDETO YURUKI $^{4}$, TOSHIHIKO MOTOHARA ${ }^{4}$, SUGURU CHIYONAGA ${ }^{4}$ and SHINICHI AKAHOSHI ${ }^{1}$ \\ ${ }^{1}$ Department of Surgery, Yamaga City Medical Center, Kumamoto, Japan; \\ ${ }^{2}$ Department of Radiology, Yamaga City Medical Center, Kumamoto, Japan; \\ ${ }^{3}$ Department of Medical Oncology, Yamaga City Medical Center, Kumamoto, Japan; \\ ${ }^{4}$ Department of Gastroenterology, Yamaga City Medical Center, Kumamoto, Japan
}

\begin{abstract}
Background: Lenvatinib, a newly developed oral multi-tyrosine kinase inhibitor, has amazing potential in the multidisciplinary treatment of advanced or metastatic hepatocellular carcinoma. Thrombocytopenia is a serious adverse event that causes drug dose reduction or withdrawal. Partial splenic embolization is currently being used as a non-surgical treatment for thrombocytopenia caused by various pharmacotherapies. Case Report: Partial splenic embolization was performed for three patients with hepatocellular carcinoma receiving lenvatinib therapy with/without transarterial chemoembolization. Partial splenic embolization was advantageous for various situations, including the induction of lenvatinib for patients with thrombocytopenia, application of lenvatinib after multiple transarterial chemoembolization using cisplatin and radiotherapy, and re-administration of lenvatinib after lenvatinib therapy-induced thrombocytopenia. In all cases, lenvatinib therapy was completed without need for cessation due to thrombocytopenia. Conclusion: We strongly recommend the new concept of combining partial splenic embolization and lenvatinib therapy for hepatocellular carcinoma.
\end{abstract}

Multidisciplinary treatment, including molecular targeted therapy, is recommended for advanced or metastatic hepatocellular carcinoma (HCC) (1-4). Lenvatinib is a newly

Correspondence to: Toru Beppu, MD, Ph.D., FACS, Department of Surgery, Yamaga City Medical Center, 511 Yamaga, Kumamoto, 861-0593, Japan. Tel: +81 968442185, Fax: +81 968442420, e-mail: tbeppu@yamaga-mc.jp

Key Words: Partial splenic embolization, hepatocellular carcinoma, lenvatinib therapy. developed oral multi-tyrosine kinase inhibitor that can provide greater tumor regression and tumor necrosis compared to sorafenib (5-7). Since March 2018, lenvatinib has become available for use in the treatment of HCC in Japan and its use has been spreading globally (8-10).

Lenvatinib is generally indicated for patients with good liver functional reserve, i.e. those with Child-Pugh score of 5 or 6 points $(5,6)$. Nonetheless, even for patients with advanced HCC who have chronic liver disease, lenvatinib was reported to have an acceptable safety profile $(4,9,10)$. The phase III REFLECT trial comparing lenvatinib and sorafenib demonstrated different adverse events profiles. Accordingly, more than $5 \%$ patients in the lenvatinib group developed several grade three or more adverse events, including hypertension $(23 \%)$, reduced appetite $(5 \%)$, reduced weight $(8 \%)$, protein urine $(6 \%)$, reduced platelet count $(5 \%)$, elevated aspartate aminotransferase (5\%), and increased blood bilirubin (7\%). (6) The lenvatinib group had fewer instances of palmar-plantar erythrodysesthesia (27\%) than the sorafenib group (52\%). Moreover, a systematic review and meta-analysis for lenvatinib cancer therapy demonstrated that thrombocytopenia (25.4\%), hypertension (17.7\%), and peripheral edema $(15.5 \%)$ were the most frequent adverse events (grade $\geq 3$ ) (11).

Partial splenic embolization (PSE) has been developed as a non-surgical treatment for alterations in blood cell count, especially platelet count (12-14). However, hypersplenism due to liver cirrhosis has remained the main reason for application of PSE. Recently, indications for PSE have expanded to include coexisting hypersplenism in chemotherapy patients, pretreatment for antiviral therapy of hepatitis virus infection, and thrombocytopenia caused by oxaliplatin- or cisplatin-containing chemotherapy (15-19).

We believe that PSE can play a key role in the continuation of lenvatinib therapy for HCC. Therefore, we retrospectively 
Table I. Patient characteristics.

\begin{tabular}{|c|c|c|c|}
\hline & & Patient & \\
\hline Characteristic & 1 & 2 & 3 \\
\hline Age, years & 65 & 66 & 60 \\
\hline Gender & Female & Male & Male \\
\hline Etiology & HCV (SVR) & Alcoholic cirrhosis & HCV cirrhosis \\
\hline Child-Pugh classification (score) & A (6) & A (6) & A (6) \\
\hline Interval from initial treatment for HCC to LEN, days & 658 & 1693 & 2902 \\
\hline \multicolumn{4}{|l|}{ Platelet count, $\times 10^{4} / \mu \mathrm{l}$} \\
\hline Before PSE & 5.0 & 5.2 & 7.7 \\
\hline Before LEN & 7.0 & 12.7 & 14.3 \\
\hline $\begin{array}{l}\text { Prior treatment for } \mathrm{HCC} \\
\text { RT 2, PSE } 2\end{array}$ & HR 2, TACE 3, & TACE 5, RT 1, PSE 2 & $\begin{array}{c}\text { HR+ RFA } 1, \text { sorafenib, } \\
\text { TACE } 2, \text { RT } 1\end{array}$ \\
\hline Pre-PSE splenic volume, $\mathrm{ml}$ & 335 & 341 & 640 \\
\hline Splenic embolized volume, $\mathrm{ml}$ & 137 & 286 & 516 \\
\hline Splenic embolized rate, $\%$ & 40.8 & 83.8 & 80.6 \\
\hline Cause of LEN introduction & Liver, bone & Liver, bone & Liver, lymph node \\
\hline Starting dose of LEN, mg & 8 & 12 & 8 \\
\hline Period of taking LEN until the end of October 2019, days & 114 & 224 & 198 \\
\hline Adverse event grade $\geq 3$ after LEN therapy* & Hepatic injury, herpes zoster & Hand-foot syndrome & Hypothyroidism, fatigue \\
\hline
\end{tabular}

HCV: Hepatitis C virus; SVR: sustained virologic response; HCC: hepatocellular carcinoma; LEN: lenvatinib; PSE: partial splenic embolization; HR: hepatic resection; TACE: transarterial chemoembolization; RT: radiotherapy; RFA: radiofrequency ablation. *By Common Terminology Criteria for Adverse Events version 4.0 (28).

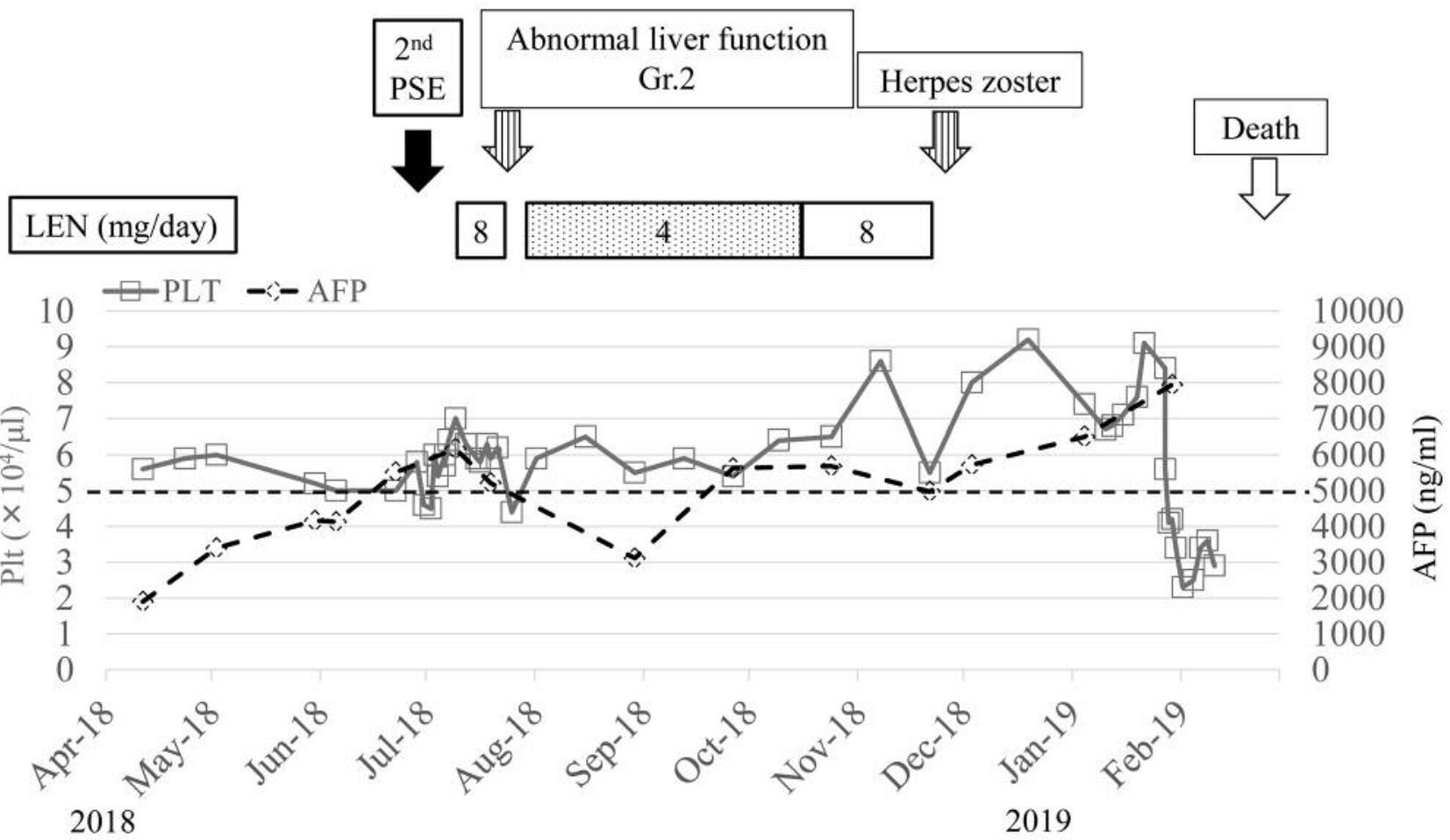

Figure 1. Treatment course and changes in alpha fetoprotein (AFP) level. PLT, Platelets; PSE: partial splenic embolization; LEN: lenvatinib; Gr.: grade by Common Terminology Criteria for Adverse Events version 4.0 (28). 


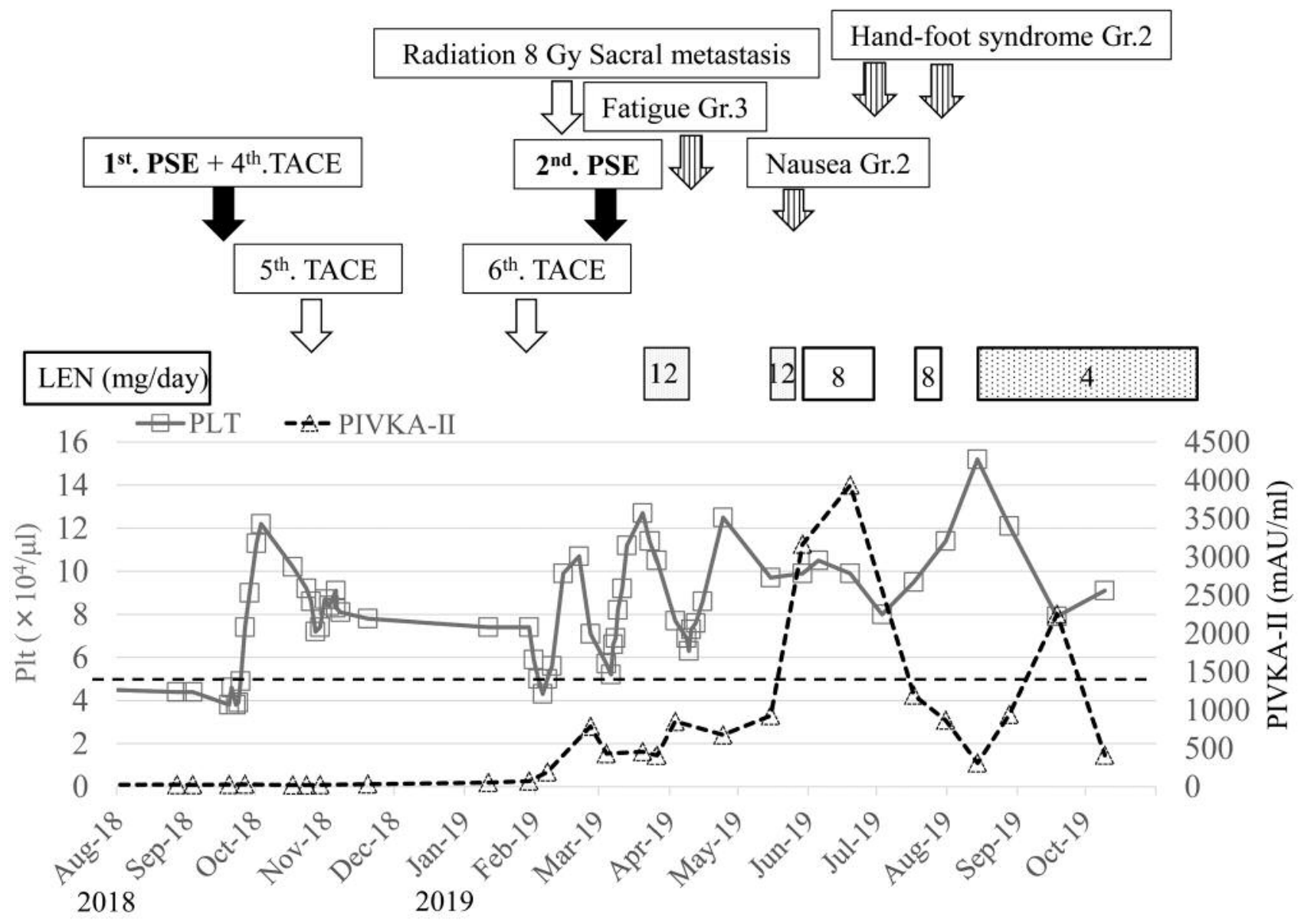

Figure 2. Treatment course and changes in protein induced by vitamin K absence or antagonist-II (PIVKA-II) level. PLT: Platelets; PSE: partial splenic embolization; LEN: lenvatinib; Gr.: grade by Common Terminology Criteria for Adverse Events version 4.0 (28).

analyzed data for patients with HCC treated with PSE across various situations: before or during lenvatinib therapy with/without transarterial chemoembolization (TACE).

\section{Case Report}

Clinical characteristics and details of PSE and lenvatinib therapy in three patients are summarized in Table I.

Case 1. A 65-year-old woman with $\mathrm{HCC}$ and sustained virologic response of hepatitis $\mathrm{C}$ virus was referred to our hospital 3 years and 9 months ago and underwent two laparoscopic liver resections. After 15 months, she was diagnosed with unresectable multiple HCC and TACE was performed twice alone and in combination with first PSE. Prior to lenvatinib therapy, second PSE was conducted. Treatment course and changes in alpha fetoprotein (AFP) level were demonstrated (Figure 1). One year and a half later, she received radiotherapy twice for cancer pain related to multiple bone metastases, and TACE was performed a third time between the two radiotherapies. After the second PSE, lenvatinib was started and continued for 114 days. Lenvatinib was discontinued because of tumor progression and herpes zoster infection. Unfortunately, the patient died 3 months after discontinuing lenvatinib.

Case 2. First TACE for a 66-year-old man with HCC in alcoholic cirrhosis had been performed at another hospital 5 years and 3 months earlier. Two years later, TACE was performed three times to treat newly developed HCC. The first PSE was performed with the fourth TACE to minimize platelet decrease induced by TACE using cisplatin (18). Treatment course and changes in protein induced by vitamin $\mathrm{K}$ absence or antagonist-II (PIVKA-II) level were recorded (Figure 2). During the two additional TACE treatments, the platelet count remained $\geq 5.0 \times 10^{4} / \mu$, but tumor response was 


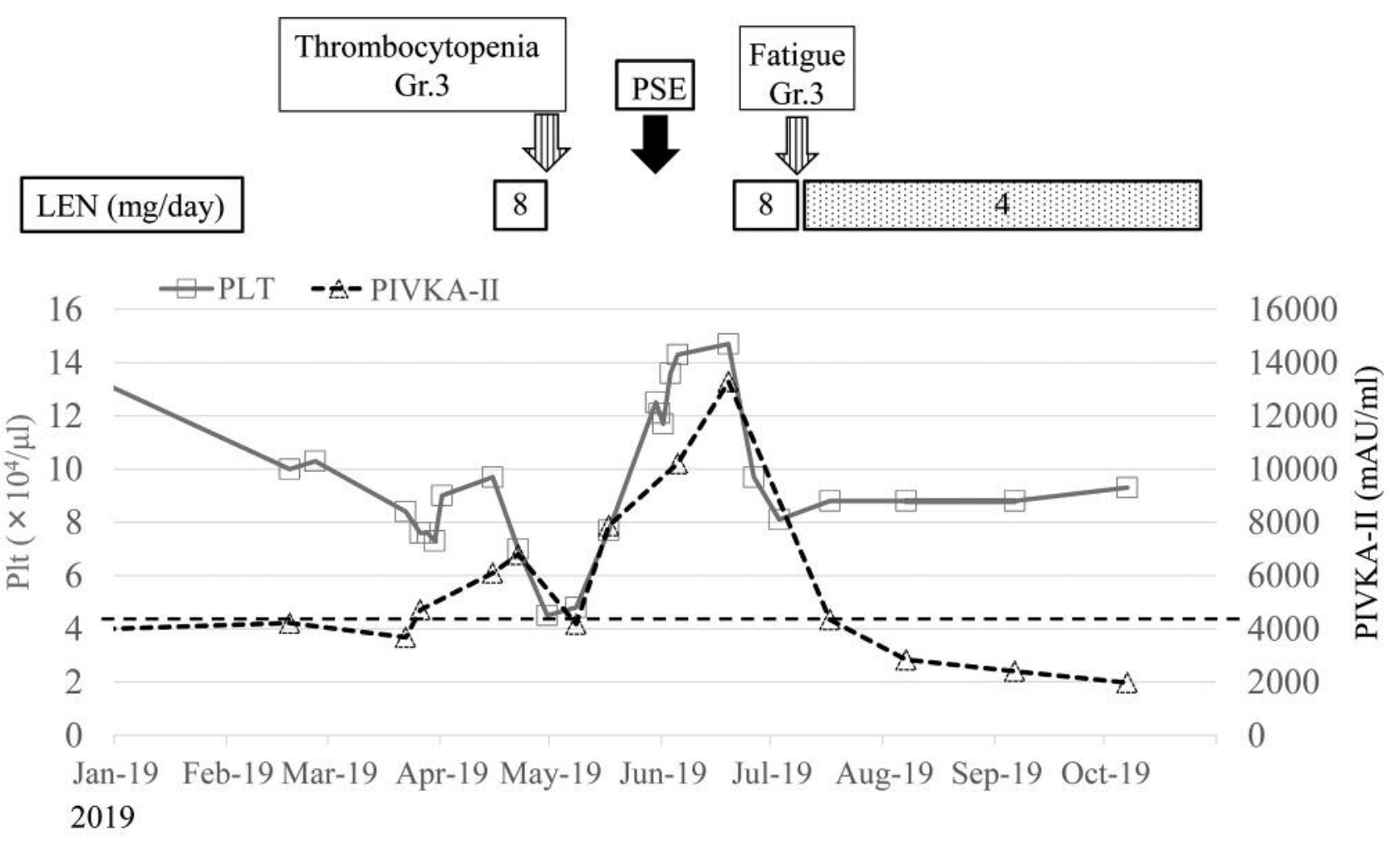

Figure 3. Treatment course and change in protein induced by vitamin K absence or antagonist-II (PIVKA-II) level. PLT: Platelets; PSE: partial splenic embolization; TACE, transarterial chemoembolization; LEN: lenvatinib; Gr.: grade by Common Terminology Criteria for Adverse Events version $4.0(28)$.

insufficient. Sacral bone metastasis was treated using radiotherapy. The second PSE was performed before introducing lenvatinib. Lenvatinib administration was continued for 7 months and was ongoing at the time of writing, however, the dose administered was reduced from 12 to $4 \mathrm{mg}$ due to reasons other than thrombocytopenia. Nonetheless, platelet count was maintained at $\geq 8.0 \times 10^{4} / \mu 1$.

Case 3. A 66-year-old man with HCC and hepatitis $\mathrm{C}$ was referred to our hospital. He had been diagnosed with HCC 8 years earlier and had undergone liver resection at another hospital. Immediately after surgery, sorafenib was started and continued for about 6.5 years to treat the diagnosed intrahepatic and pulmonary metastases. Sorafenib administration was performed irregularly. Unfortunately, details remain unknown. The patient was then referred to our hospital because of uncontrolled primary HCC and multiple intra-abdominal lymph node metastases. Treatment course and changes in PIVKA-II level were recorded (Figure 3). Although lenvatinib therapy was started, grade 3 thrombocytopenia was observed 2 weeks later. After performing PSE, lenvatinib administration was continued providing that the platelet count was maintained at $>8.0 \times 10^{4} / \mu 1$. The PIVKA-II level dramatically decreased due to tumor necrosis of bulky paraaortic lymph node metastases (Figure 4). Lenvatinib was continued for more than 6 months, during which the patient was doing well with no symptoms.

\section{Discussion}

The application of PSE for patients with $\mathrm{HCC}$ receiving lenvatinib treatment is a new concept. We did not find any article in PubMed using the key words "partial splenic embolization" and "lenvatinib" until November 1, 2019. The current study showed that PSE was quite beneficial for improving thrombocytopenia in various situations, including in the induction of lenvatinib for patients with insufficient platelet count (Case 1), application of lenvatinib after multiple TACE using cisplatin and radiotherapy (Case 2), and re-administration of lenvatinib after thrombocytopenia caused by prior lenvatinib therapy (Case 3). In all cases, lenvatinib therapy was completed without cessation caused by thrombocytopenia. Thrombocytopenia can be caused by coexisting liver cirrhosis and lenvatinib therapy. Approximately a quarter of the patients met lenvatinib administration criteria (platelet count $\left.\geq 7.5 \times 10^{4} / \mu \mathrm{l}\right)(5,6)$, and 


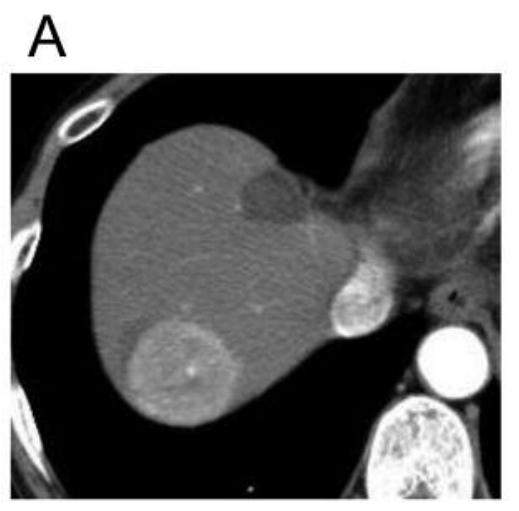

D

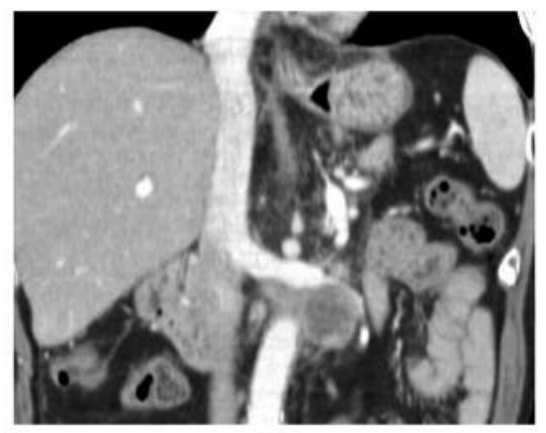

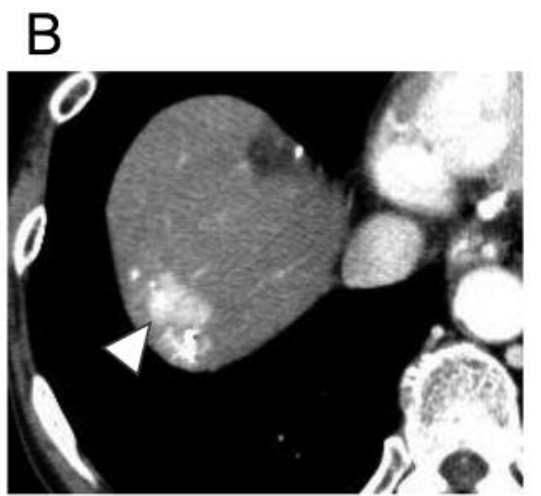

$\mathrm{E}$

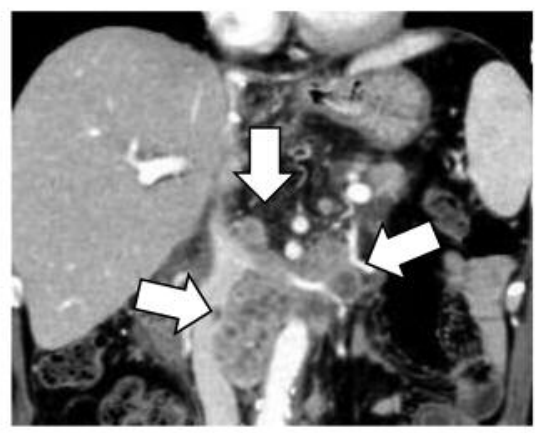

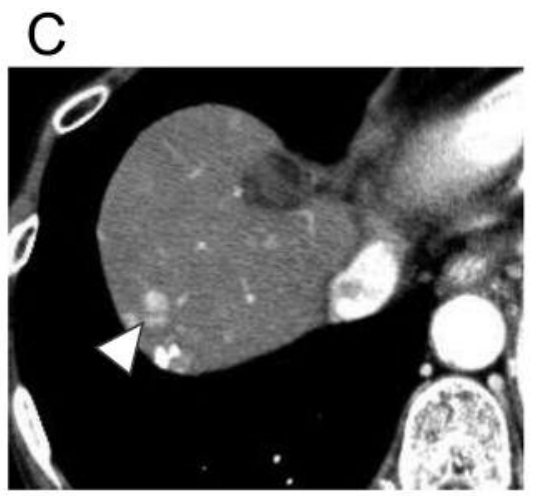

$\mathrm{F}$

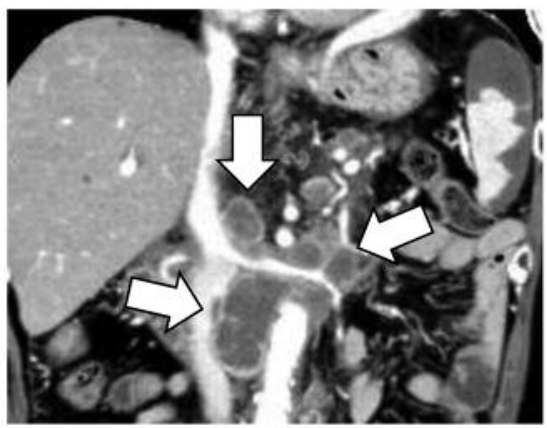

Figure 4. Changes in computed tomography findings for case 3. Axial contrast-enhanced computed tomography scans showing a primary liver tumor upon referral to our hospital (A), before lenvatinib therapy $(B)$, and 5 months after treatment $(C)$. Coronal contrast-enhanced computed tomographic scans showing multiple intra-abdominal lymph node metastases upon referral to our hospital $(D)$, before lenvatinib therapy $(E)$, and 5 months after treatment $(F)$. Liver tumor (arrow head) had decreased in size (40\% reduction in diameter) but this was accompanied by obvious enhancement $(B, C)$. Para-aortic lymph node metastases (arrow) showed complete necrosis in the tumor area after lenvatinib therapy $(E, F)$.

adverse events (grade $\geq \mathrm{D} 3$ ) of thrombocytopenia had been demonstrated (11). Because platelet-derived growth factor is known to promote platelet recovery and the development of bone marrow colony-forming unit-megakaryocytes (20), its inhibition by lenvatinib might induce thrombocytopenia.

Currently, PSE has been widely used for patients with thrombocytopenia as a result of various pharmacotherapies, including antiviral, platinum, or targeted drugs (15-19). PSE is not beneficial for patients with hypersplenism with poor bone marrow function. To avoid meaningless PSE, determining the presence of splenomegaly using diagnostic images and assessing immature platelet fraction in the peripheral blood are imperative $(21,22)$. Moreover, a bone marrow aspiration test is needed for certain cases. From the point of view of safety, excessive embolization (infarcted splenic volume $\geq 540 \mathrm{ml}$ ) and application of PSE for patients with Child-Pugh class C should be avoided (13). However, in patients with a large spleen $(>700 \mathrm{ml})$, repeated PSE is recommended to avoid serious complications (23). In the present study, only mild fever and abdominal pain were observed as complications of PSE during some preoperative days. No serious complications, including overwhelming sepsis, were observed.

Considering that long-term lenvatinib administration is required to achieve excellent antitumor effect, a prolonged increase in platelet count after PSE is essential. We have already reported positive correlation between infarcted splenic volume and increase in platelet count (12). Accordingly, a cut-off for infarcted splenic volume of 388 $\mathrm{ml}$ was needed to increase platelet count by $5.0-8.0 \times 10^{4} / \mu \mathrm{l}$ over 1 year. Because an infarcted splenic volume of $516 \mathrm{ml}$ was achieved in case 3 , lenvatinib therapy was continued for more than 6 months. In case 2 , the infarcted splenic volume was only $286 \mathrm{ml}$ because of a relatively small spleen, however, the platelet count was maintained at $>5.0 \times 10^{4} / \mu \mathrm{l}$ for 7 months. In case 3, multiple HCC and lymph node metastases were initially treated with TACE using cisplatin lipiodol and radiotherapy, respectively. Due to insufficient antitumor effect, lenvatinib was started followed by reintroduction of lenvatinib after PSE. Interestingly the 
antitumor effect was different for the primary liver tumor and para-aortic lymph node metastases. Because the obvious tumor necrosis effect observed was limited to lymph node metastases, additional TACE will be planned for this case.

It has been reported that simultaneous hepatectomy and splenectomy in patients with HCC was associated with better tumor-free or disease-free survival compared to hepatectomy alone $(24,25)$. Another study has shown that spleen size affected postoperative HCC recurrence and overall survival after liver resection (26). It is suspected that the spleen may inhibit immunological function in patients with HCC because higher levels of T-helper cytokine interleukin-2 and interferon- $\gamma$ and lower levels of interleukin-10 were observed in hepatectomy and splenectomy groups (24). Furthermore, studies have shown that splenectomy increased the number of natural killer cells (27). Similarly, better antitumor immunological function can be obtained after PSE, which will have a synergistic effect with lenvatinib.

In conclusion, PSE is a safe and quite beneficial tool for patients with HCC receiving lenvatinib. Further investigations will be required to determine patient selection, as well as optimal timing for performing PSE and the optimal infarcted volume of PSE.

\section{Conflicts of Interest}

The Authors have no conflicts of interest.

\section{Authors' Contributions}

NS and TB identified the concept and wrote the draft of the article; all Authors actually performed interventional or medical treatments; NS, TB, KK, KS, SY, TM, SC, and SA provided critical revisions.

\section{References}

1 Naugler WE, Alsina AE, Frenette CT, Rossaro L and Sellers MT: Building the multidisciplinary team for management of patients with hepatocellular carcinoma. Clin Gastroenterol Hepatol 13: 827-835, 2015. PMID: 24909910. DOI: 10.1016/j.cgh.2014. 03.038

2 Forner A, Reig M and Bruix J: Hepatocellular carcinoma. Lancet 9: 1301-1314, 2018. PMID: 29307467. DOI: 10.1016/S01406736(18)30010-2

3 Takeyama H, Beppu T, Higashi T, Kaida T, Arima K, Taki K, Imai K, Nitta H, Hayashi H, Nakagawa S, Okabe H, Hashimoto D, Chikamoto A, Ishiko T, Tanaka M, Sasaki Y and Baba H: Impact of surgical treatment after sorafenib therapy for advanced hepatocellular carcinoma. Surg Today 48: 431-438, 2018. PMID: 29110089. DOI: $10.1007 / \mathrm{s} 00595-017-1603-x$

4 Sato N, Beppu T, Kinoshita K, Yuki H, Suyama K, Chiyonaga S, Motohara T, Komohara Y, Hara A and Akahoshi S: Conversion hepatectomy for huge hepatocellular carcinoma with arterioportal shunt after chemoembolization and lenvatinib therapy. Anticancer Res 39: 5695-5701, 2019. PMID: 31570469. DOI: $10.21873 /$ anticanres. 13768
5 Ikeda K, Kudo M, Kawazoe S, Osaki Y, Ikeda M, Okusaka T, Tamai T, Suzuki T, Hisai T, Hayato S, Okita K and Kumada H: Phase 2 study of lenvatinib in patients with advanced hepatocellular carcinoma. J Gastroenterol 52: 512-519, 2017. PMID: 27704266. DOI: 10.1007/s00535-016-1263-4

6 Kudo M, Finn RS, Qin S, Han KH, Ikeda K, Piscaglia F, Baron A, Park JW, Han G, Jassem J, Blanc JF, Vogel A, Komov D, Evans TRJ, Lopez C, Dutcus C, Guo M, Saito K, Kraljevic S, Tamai T, Ren M and Cheng AL: Lenvatinib versus sorafenib in first-line treatment of patients with unresectable hepatocellular carcinoma: a randomised phase 3 non-inferiority trial. Lancet 391: 1163-1173, 2018. PMID: 29433850. DOI: 10.1016/S01406736(18)30207-1

7 Matsuki M, Hoshi T, Yamamoto Y, Ikemori-Kawada M, Minoshima Y, Funahashi Y and Matsui J: Lenvatinib inhibits angiogenesis and tumor fibroblast growth factor signaling pathways in human hepatocellular carcinoma models. Cancer Med 7: 2641-2653, 2018. PMID: 29733511. DOI: 10.1002/ cam4.1517

8 Hiraoka A, Kumada T, Atsukawa M, Hirooka M, Tsuji K, Ishikawa T, Takaguchi K, Kariyama K, Itobayashi E, Tajiri K, Shimada N, Shibata H, Ochi H, Tada T, Toyoda H, Nouso K, Tsutsui A, Nagano T, Itokawa N, Hayama K, Imai M, Joko K, Tanaka H, Tamai T, Koizumi Y, Hiasa Y, Michitaka K, Kudo M; Real-life Practice Experts for HCC (RELPEC) Study Group, HCC 48 Group (hepatocellular carcinoma experts from 48 clinics in Japan): Important clinical factors in sequential therapy including lenvatinib against unresectable hepatocellular carcinoma. Oncology 15: 1-9, 2019. PMID: 31307035 . DOI: $10.1159 / 000501281$

9 Hiraoka A, Kumada T, Atsukawa M, Hirooka M, Tsuji K, Ishikawa T, Takaguchi K, Kariyama K, Itobayashi E, Tajiri K, Shimada N, Shibata H, Ochi H, Tada T, Toyoda H, Nouso K, Tsutsui A, Nagano T, Itokawa N, Hayama K, Imai M, Joko K, Koizumi Y, Hiasa Y, Michitaka K, Kudo M; Real-life Practice Experts for HCC (RELPEC) Study Group, HCC 48 Group (hepatocellular carcinoma experts from 48 clinics in Japan): Prognostic factor of lenvatinib for unresectable hepatocellular carcinoma in real-world conditions-Multicenter analysis. Cancer Med 8: 3719-3728, 2019. PMID: 31127698. DOI: 10.1002/ cam4.2241

10 Rimassa L, Danesi R, Pressiani T and Merle P: Management of adverse events associated with tyrosine kinase inhibitors: Improving outcomes for patients with hepatocellular carcinoma. Cancer Treat Rev 77: 20-28, 2019. DOI: 10.1016/ j.ctrv.2019.05.004. PMID: 31195212.

11 Zhu C, Ma X, Hu Y, Guo L, Chen B, Shen K and Xiao Y: Safety and efficacy profile of lenvatinib in cancer therapy: a systematic review and meta-analysis. Oncotarget 7: 44545-44557, 2016. PMID: 27329593. DOI: 10.18632/oncotarget.10019

12 Hayashi H, Beppu T, Masuda T, Mizumoto T, Takahashi M, Ishiko T, Takamori H, Kanemitsu K, Hirota M and Baba H: Predictive factors for platelet increase after partial splenic embolization in liver cirrhosis patients. J Gastroenterol Hepatol 22: 1638-1642, 2007. PMID: 17683504.

13 Hayashi H, Beppu T, Okabe K, Masuda T, Okabe H and Baba $\mathrm{H}$ : Risk factors for complications after partial splenic embolization for liver cirrhosis. Br J Surg 95: 744-750, 2008. PMID: 18412294. DOI: 10.1002/bjs.6081

14 Hayashi H, Beppu T, Shirabe K, Maehara Y and Baba H: Management of thrombocytopenia due to liver cirrhosis: A 
review. World J Gastroenterol 20: 2595-2605, 2014. PMID: 24627595. DOI: $10.3748 / w j g . v 20.110 .2595$

15 Kauffman CR, Mahvash A, Kopetz S, Wolff RA, Ensor J and Wallace MJ: Partial splenic embolization for cancer patients with thrombocytopenia requiring systemic chemotherapy. Cancer 112: 2283-2288, 2008. PMID: 18344210. DOI: 10.1002/cncr.23432

16 Takahara M, Miyake Y, Miyatake H, Imagawa A, Nakatsu M, Ando $\mathrm{M}$, Hirohata $\mathrm{M}$ and Yamamoto $\mathrm{K}$ : Partial splenic embolization facilitates the adherence to peginterferon in chronic hepatitis C with thrombocytopenia. Intern Med 50: 2731-2736, 2011. PMID: 22082883.

17 Kondo C, Atsukawa M, Tsubota A, Shimada N, Abe H, Itokawa N, Nakagawa A, Fukuda T, Matsushita Y, Nakatsuka K, Kawamoto C, Iwakiri K, Aizawa Y and Sakamoto C: Safety and efficacy of partial splenic embolization in telaprevir-based triple therapy for chronic hepatitis C. Intern Med 54: 119-126, 2015. DOI: 10.2169 /internalmedicine.54.3066

18 Huang JH, Gao F, Gu YK, Li WQ and Lu LW: Combined treatment of hepatocellular carcinoma with partial splenic embolization and transcatheter hepatic arterial chemoembolization. World J Gastroenterol 13: 6593-6597, 2007. PMID: 18161933. DOI: 10.3748/wjg.v13.i48.6593

19 Luz JH, Luz PM, Marchiori E, Rodrigues LA, Gouveia HR, Martin HS, Faria IM, Souza RR, Gil RA, Palladino AM, Pimenta KB and de Souza HS: Partial splenic embolization to permit continuation of systemic chemotherapy. Cancer Med 5: 2715-2720, 2016. PMID: 27611010. DOI: $10.1002 / \mathrm{cam} 4.856$

20 Bergsten E, Uutela M, Li X, Pietras K, Ostman A, Heldin CH, Alitalo $\mathrm{K}$ and Eriksson U: PDGF-D is a specific, protease activated ligand for the PDGF beta-receptor. Nat Cell Biol 3: 512-516, 2001. PMID: 11331881. DOI: $10.1038 / 35074588$

21 Briggs C: Quality counts: new parameters in blood cell counting. Int J Lab Hematol 31: 277-297, 2009. PMID: 19452619. DOI: 10.1111/j.1751-553x.2009.01160.x

22 Imai K, Emi Y, Iyama KI, Beppu T, Ogata Y, Kakeji Y, Samura H, Oki E, Akagi Y, Maehara Y, Baba H; Kyusyu Study Group of Clinical Cancer (KSCC) ancillary study: Splenic volume may be a useful indicator of the protective effect of bevacizumab against oxaliplatin-induced hepatic sinusoidal obstruction syndrome. Eur J Surg Oncol 40: 559-566, 2014. PMID: 24388740. DOI: 10.1016/j.ejso.2013.12.009
23 Hayashi H, Beppu T, Okabe K, Masuda T, Okabe H, Ishiko T and $\mathrm{Baba} \mathrm{H}$ : Therapeutic factors considered according to the preoperative splenic volume for a prolonged increase in platelet count after partial splenic embolization for liver cirrhosis. J Gastroenterol 45: 554-559, 2010. PMID: 20047119. DOI: 10.1007/s00535-009-0185-9

24 Chen XP, Wu ZD, Huang ZY and Qiu FZ: Use of hepatectomy and splenectomy to treat hepatocellular carcinoma with cirrhotic hypersplenism. Br J Surg 92: 334-339, 2005. PMID: 15672441. DOI: $10.1002 /$ bjs.4776

25 Zhang XY, Li C, Wen TF, Yan LN, Li B, Yang JY, Wang WT and Jiang L: Synchronous splenectomy and hepatectomy for patients with hepatocellular carcinoma and hypersplenism: A case-control study. World J Gastroenterol 21: 2358-2366, 2015. PMID: 25741142. DOI: 10.3748/wjg.v21.i8.2358

26 Takeishi K, Kawanaka H, Itoh S, Harimoto N, Ikegami T, Yoshizumi T, Shirabe K and Maehara Y: Impact of splenic volume and splenectomy on prognosis of hepatocellular carcinoma within Milan criteria after curative hepatectomy. World J Surg 42: 1120-1128, 2018. PMID: 28920178. DOI: $10.1007 / \mathrm{s} 00268-017-4232-\mathrm{z}$

27 Shimada M, Hashizume M, Shirabe K, Takenaka K and Sugimachi K: A new surgical strategy for cirrhotic patients with hepatocellular carcinoma and hypersplenism. Performing a hepatectomy after a laparoscopic splenectomy. Surg Endosc 14: 127-130, 2000. PMID:10656943. DOI: 10.1007/s004649900082

28 U.S. Department of Health and Human Services NIH, National Cancer Institute: Common Terminology Criteria for Adverse Events (CTCAE) Version 4.0. NIH publication 09-5410.

Received November 7, 2019

Revised November 12, 2019

Accepted November 15, 2019 